\title{
Adaptive and Intelligent E-Portfolio Architecture for Learning
}

\author{
Dekson D.E. \\ Research Scholar \\ Educational media center \\ NITTTR, Chennai
}

\author{
Suresh E.S.M. \\ Associate Professor \\ Educational media center \\ NITTTR, Chennai
}

\begin{abstract}
E-learning system is gaining more and more importance in the new millennium for imparting education and training. In this work, a novel E-portfolio architecture is being proposed and a model was developed which provides adaptive and interactive content for teaching programming languages where we can trace the sequence of execution of the program and the arrangement of data in the memory, which gives a clear visualization of the program. The model developed can be used for training learners on programming. This can be implemented in classroom teaching and also can be made online. Online chat is also provided for discussions and facility to post the doubts and clarify them immediately without disturbing the class.
\end{abstract}

Considering the fact that not just delivering content would be sufficient, and more features would be expected from the modern learners, the e-portfolio system is embedded with adaptability and made interactive. The E-portfolio designed will be flexible for the learner by implementing the need based learning styles of the learner. The flash animations and three-dimensional images along with audio and video can be used to make the content live. The learners are analyzed by offering them different questions and judge their learning styles and based on this outcome they are given variants of learning content. This paper describes the architecture of an interactive and adaptive E-portfolio for enhancing the learning process.

\section{Keywords}

E-portfolio, E-learning, adaptive learning, multimedia learning, learning styles, Web based learning, Real-time Assistance.

\section{INTRODUCTION}

Nowadays the technology is growing very fast. Mainly the World Wide Web is emerging with new technologies day by day[4]. This web made the world as an e-village or global village. It became very common to have a computer system connected to Internet in each and every house. So we choose to develop an Eportfolio based teaching system[10][14][18], which is available through web also.

E-portfolio is defined as "collection of authentic and diverse evidence, drawn from a larger archive, which represents what a person or an organization has learned over time, on which the person or organization has reflected, designed for presentation to one or more audiences for a particular rhetorical purpose". Eportfolio is a product as the result of a process [7][17].

The same E-portfolio in the context of teaching is defined as "digitized collection of artifacts including demonstrations, resources and accomplishments that represent an individual, curriculum, group or institution". This collection can be comprised of text based, graphic, pictorial or multimedia elements with some added features archived on a website and or on other electronic media such as a CD-ROM or DVD. The use of computer animation help to support the learning of engineering subjects[8][13][15]. Holzinger et.al. [3] have found that the dynamic media can support learning when cognitive load and learners' mental representations are taken into account during the design and development of learning material containing dynamic media. E-portfolios have the potential to enhance teaching, learning and assessment practices. E-portfolios encourage education and training and often involve the exchange of ideas and feed back.

The E-portfolio developed will be made adaptive by employing adaptive hypermedia environments and learning styles research[12]. In this system, our main objective is to encourage education and training by presenting the same content in the learner's mode and often involve the exchange of ideas, regular self-evaluation of the students and feedback.

The paper is organized as follows: Section 2 gives the background work regarding e-portfolios. Section 3 deals with the proposed system architecture and a model for teaching programming languages. Section 4 discuses the working of the system. Finally the conclusion is given in section 5 .

\section{BACKGROUND}

In the early days of education, there was only one medium to learn that was classroom teaching. Gradually the research in the education derived some solutions such as paper based material distribution, and with the development of multimedia the same material was distributed in the form of Compact Disks. These helped the students who are unable to go to the schools or colleges. This type of learning failed due to lack of interaction as in classroom. Then the research was again started to create the interaction as in classroom that leads to development of a system ALN (Asynchronous Learning Networks). With the help of 
Internet they transmitted the video and audio records of classroom teaching to their students, provided remote login to the classes. This is the base for the web-based learning.

There are so many developments going on for web based learning, some of them are mentioned here. Christian wolf, in his work of iWeaver [11] he proposed a model in which he categorized the learners and then the same content is delivered in different modes such as plain text, pictorial, derivative or relational and animation[16]. He also provided different tools to switch from one mode to another mode. In the web-based learning, students who are habituated with traditional textbook reading and having less knowledge on the hypertext find it difficult to access the hypertext and search the required data. Navigational maps will help them from disorientation [1]. Mohamed Jemni, Issam Ben Ali [6] developed a system called PERSO which reduces the lecturers work to clarify the doubts and to give the immediate answers to the student from a stored database. Joyce Pittman et al[2] have concluded that the learning styles could influence content type preferences among students in either environment (face-to-face or online) but this hypothesis needs more research. In this system the learners with different learning goals are treated differently.

Some researchers proposed that using the animations we can easily deliver the content to the learners and it helps them for quick understanding and also useful for simulation [19][20]. The presentation of concepts using animations instead of simple text or pictures will form mental models that can easily exist in brain [9]. These visualization or animations can be seen as a simplification of complex models with the aid of moving figures and lines. These interactive visualizations and simulations can also demonstrate the conditions of actions and events in the real world and subsequently support a constructive learning approach which is more student centered [5]. Also explained in his paper providing some tools to examine the student's perception will help them to evaluate their self.

The web-based learning is advanced more in such a way that to create a virtual class room with a populated actor as assistant professor and adding some facial expressions to that picture helps to interact with the students. Despite these some people say that with these animations students are deviating from the studies and concentrating on the animations. Also said e-books are giving good results than animations.

In this paper, the proposed E-portfolio architecture is designed for teaching programming languages. The learners who are new to technical education or engineering graduation will have very less knowledge about computers and programming languages [16]. So if the lecturers try to load the new paradigms or concepts with the traditional teaching methods and techniques the learners' fail to grasp the new concepts. Here we list some of the problems faced by novice learners with the traditional teaching methods that we come to know through survey from novice learners.
1. Difficult to understand the new paradigms like procedural or object oriented programming concepts.

2. Lack of proper means to experience or visualize the concepts and the program output, makes them loose interest in learning programming languages.

3. For the distance learners and campus learners it is not possible to practice the program parallel with the lecturer, so when they are trying the same program (at their home) clarifying doubts become difficult.

So it is proved that with the help of animations, visualizations and simulations we can teach the programming languages by simplifying the complex models, interactively and make them to remember easily.

\section{PROPOSED WORK}

A system that can overcome the drawbacks mentioned above and with some added features is designed. The proposed work is to develop a teaching E-portfolio. Teaching e-portfolios derive from paper based teaching and course portfolios. Teaching E-portfolios are used for critical reflection and learning purposes; they make individual teaching practices public and therefore available for collective learning and knowledge sharing. In this system we have a collection of material presented in different formats such as textual, graphical, multimedia and simple animations. These will be presented by knowing the student's learning style. Depending on the topic difficulty level we will suggest the learner to switch to another content for a better understanding.

The following sections will explain how we designed the "Interactive e-portfolio architecture for learning" and how this can help the students to build their professional career and keep them up to date with growing technologies.

\subsection{System Architecture}

The system architecture consists of four major parts, namely Intelligence system, Content Delivery system, Studio assistants and Database as in Fig.1.

\subsubsection{Intelligence system}

This system decides the learning style of the learner. The learner initially answers a set of questions asked by the intelligence system. Based on the answers given by the learner, the intelligence system suggests a most suitable content to the learner. The intelligence system also gets the feedback from the learner after a session, and the suggestions would be considered for future modifications.

\subsubsection{Content Delivery System}

The function of the content delivery system is to deliver the content to the learner, which is suggested and preferred by the learner.

\subsubsection{Studio Assistants}

The team of studio members will consult the lecturers and prepare the learning material [21]. 


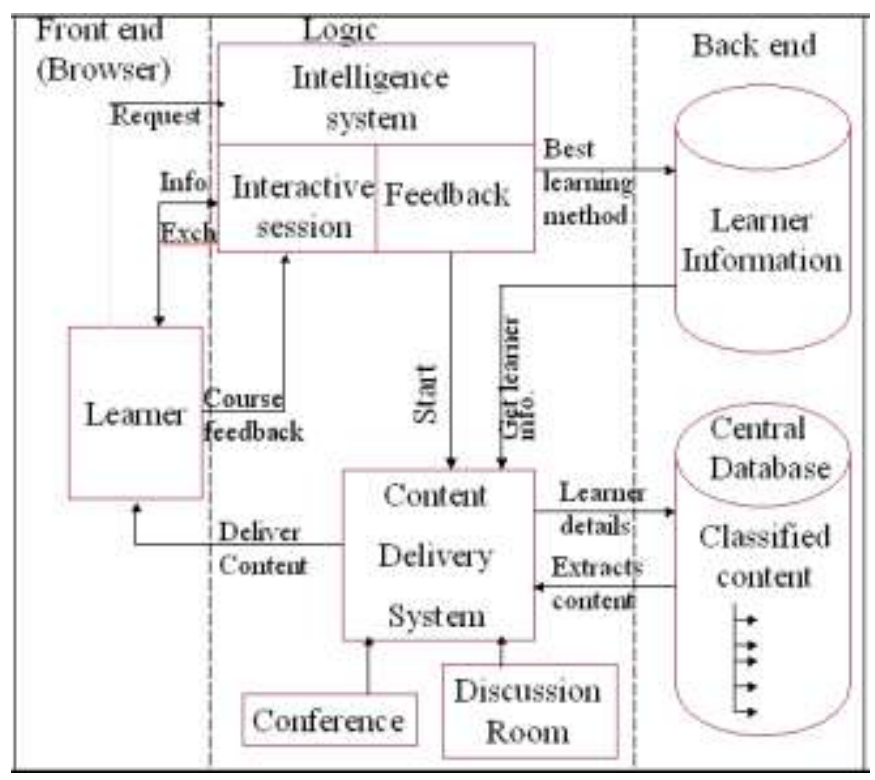

Fig.1. Architecture of the interactive e-Portfolio system.

\subsection{System Architecture model to teach programming languages}

Firstly, it is needed to discuss about the lecturer screen and student screen, which have various features. The Fig. 2 will show student screen. These screen contains the following windows.

\subsubsection{Student Window}

The student window contains the following windows: program execution window, presentation window, notes window, navigation window, and answer toolbox window.

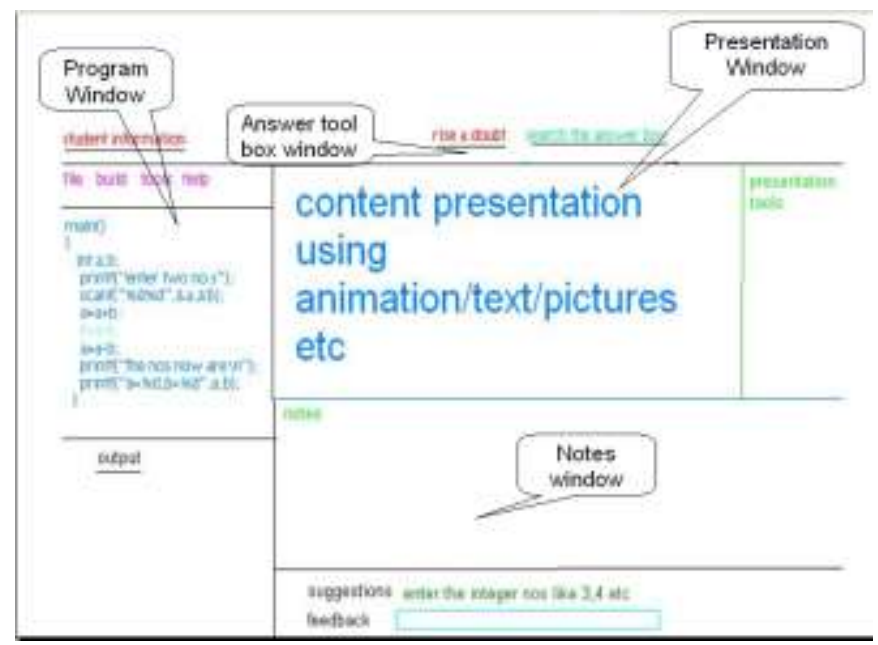

Fig.2. Typical window presented at student side

Program execution window visualizes the flow of control of the program, in which line the current explanation is going on and output is also displayed. In the presentation window the visualization of the program will be displayed. It contains some tools for the presentations. Notes window facilitates the student to take any notes on the presentation. Navigation window provides the navigation to different places. Answer toolbox window provides the search for previously answered questions and to post queries to lecturers.

\subsubsection{Faculty Window}

The features of the faculty window(Fig.3) include space for explaining the program, program execution and output and visualizations and queries posted by the students. The query window shows the status of each student whether he understood a particular line of code or not. And also the queries posted by the students. History window contains the history of program and at which lines of the program the students felt difficult to understand. It also helps him to get a feedback on his explanation.

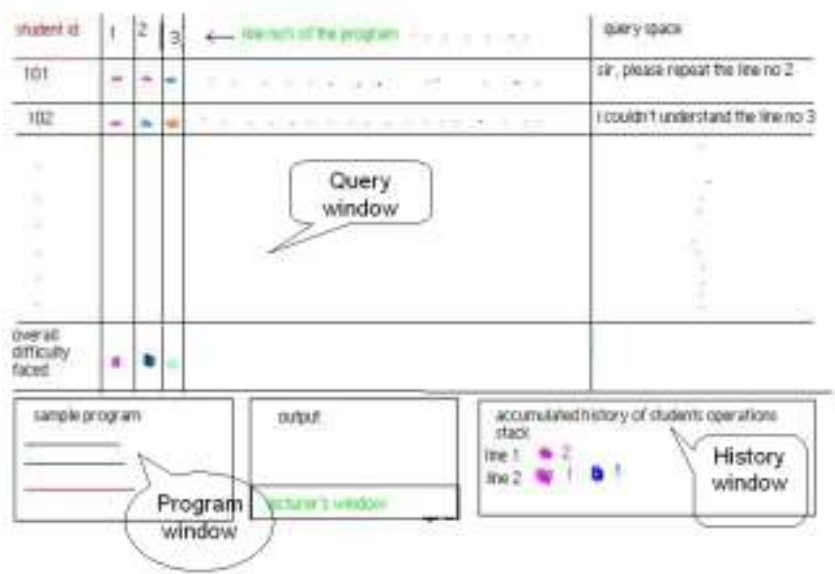

Fig.3. Typical window presented at faculty side

\section{WORKING OF THE SYSTEM}

The system judges the learning style and preference of the learner and offers content accordingly. Initially the learner interacts with the system through the intelligence module. The intelligence module in order to judge the learning style of the learner puts some questions to the learners. The learner answers these questions based on his preference and analyzing the answers the intelligence system suggest a suitable content for the learner.

The content delivery system based on the instruction from the intelligence system delivers the content to the learner. After a learning session the feedback and suggestions from the learner are also recorded for future modifications.

The system model for teaching programming languages works as follows:

Step 1: The lecturer announces the program for discussion. The studio assistants immediately share the related animations and 
visualizations to the students. The current program, which the lecturer is explaining, will be displayed on the students' screen.

Step 2: The lecturer will start discussing the program with the help of animations and visualizations. If the students have any doubt they can post their doubts as explained in the previous section using message services. The entire class room teaching is recorded and stored in the database, which can be viewed by the students later and can be used by the distance learners.

Step 3: The doubts posted by the students will be clarified by the lecturer. These questions and answers will be saved to the database for future needs. This will be helpful for the distance learners who are not participating in the program at real time, and they can post their doubts to the lecturer.

\section{CONCLUSION}

The E-portfolio architecture designed will be a friendly environment to the learner since it implements the learning style preferred by the learner. The content delivered will be adaptive to the learner. Thus improves the learning efficiency of the learner. The proposed model overcomes difficulties faced by novice learners due to current teaching methods and techniques followed by Institutions and Universities and make it easier for the students to learn programming languages. This is an efficient teaching system for teaching programming languages through online and offline. It encourages distributed learning. It features the automatic answering and gives real time experience for distance learners also.

\section{REFERENCES}

[1] Miyoung Lee and Amy L. Baylor,.’Designing Metacognitive Maps for Web-Based Learning Designing Metacognitive Maps for Web-Based Learning". Educational Technology \& Society, 9 (1),2006, Page(s) 344-348.

[2] Joyce Pittman, Eugene Rutz, and Virginia Elkins, "Technology-Enabled Content in Engineering Technology and Applied Science Curriculum: Implications for Online Content Development in Teacher Education", Journal of Interactive Online LearningVolume 5, Number 1, Spring 2006, Page(s) 3258.

[3] Holzinger, A., Kickmeier-Rust, M., \& Albert, D, "Dynamic Media in Computer Science Education; Content Complexity and Learning Performance: Is Less More?" Educational Technology \& Society, 11 (1), 2008, Page(s) 279-290.

[4] David Cordes and Allen Parrish, "Active Learning In Computer Science: Impacting Student Behavior", 32nd ASEE/IEEE Frontiers in Education Conference, November 6 - 9, 2002, Boston, MA.

[5] Andreas Holzinger and Martin Ebner, "Visualization, Animation and Simulation for Mobile Computers: Experiences from Prototypes", Central European Multimedia and Virtual Reality Conference, 2005.

[6] Mohammed JEMNI and Issam BEN ALI, "Automatic answering tool for e-learning environment".

[7] J.Wall and Dr. T. Phillips, "Technology Enabled Learning Lessons Learned from Irish Initiatives”, BEAR conference 2008.
[8] Mats Brorsson, "MipsIt - A Simulation and Development Environment Using Animation for Computer Architecture Education".

[9] Michael D. Byrne, Richard Catrambone and John T. Stasko, "Evaluating Animations as Student Aids in Learning Computer Algorithms", 1999.

[10] Aida Mysan, "Learning in the $21^{\text {st }}$ Century", Electronic Student Career Portfolios (ePortfolios).

[11] Christian Wolf, “iWeaver: Towards 'Learning Style' - based e-Learning in Computer Science Education", Australian Computing Education Conference (ACE2003), Australian Computer Society, Conferences in Research and Practice in Information Technology, Vol. 20.

[12] Tomsaz Muldner, Elhadi Shakshuki, Andreas Kerren, Zhinan Shen, Xiaoguang Bai, "Using Structured Hypermedia to explain Algorithms", IADIS International Conference e-Society 2005.

[13] Christopher W. Trueman, "Teaching Transmission Line Transients Using Computer Animation", 29 $9^{\text {th }}$ ASEE/IEEE Frontiers in Education Conference, November 10-13, 1999.

[14] Azzedine Lansari and Abdallah Tubaisht, "Using an Outcome-Based Information Technology Curriculum and an ELearning Platform to Facilitate Student Learning", Issuses in Information Science Information Technology, Vol. 4, 2007, Page(s) 461-471.

[15] Daniela Chuda, "Visualization in Education of Theoritical Computer Science", International Conference on Computer Systems and Technologies - CompSysTech 2007, Vol. 4, Page(s) 15.1-15.6.

[16] Youzou Miyadera, Kunimi Kurasawa, Shoichi Nakamura, Nobuyoshi Yonezawa and Setsuo Yokoyama, "A Real-time Monitoring System for Programming Education using a Generator of Program Animation Systems", Journal of Computers, Vol. 2, No. 3, May 2007, Page(s)12-20.

[17] Serge Ravet, "For an ePortfolio enabled architecture", Position Paper (V 1.1).

[18] J.Higdon, T.Tran, "E-Portfolios for reflective learning", EPortfolios: Research and Practices, Western Regional Conference, 2005.

[19] Matsuda, Hiroshi, Shindo, Yoshiaki, "Education System Using Interactive 3D Computer Graphics (3D-CG) Animation and Scenario Language for Teaching Materials", Innovations in Education \& Teaching International, Vol. 43, No. 2, Page(s) 163 182, May 2006.

[20] Caryn Meissner, "Animation Brings Life to Science", Science Animations, Lawrence Livermore National Laboratory, S\&TR March/April 2008, Page(s) 17-19.

[21] Maria Dolores Afonso Suarez, Cayetano Guerra Artal, Francisco Mario Tejera Hernandez, "E-learning multimedia applications: Towards an engineering of content creation" Int. J. of Computers, Communications \& Control, ISSN 1841-9836, EISSN 1841-9844,Vol. III (2008), No. 2, pp. 116-124. 